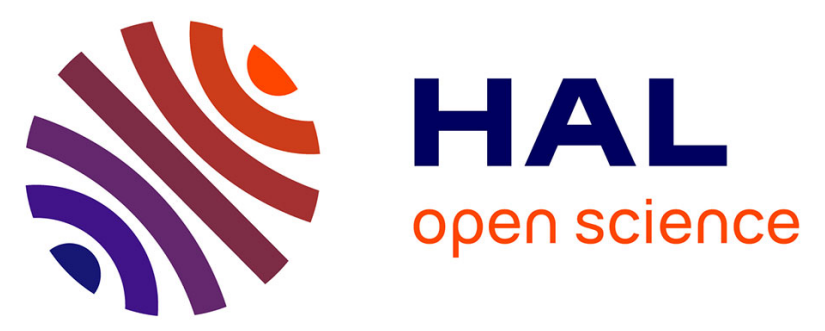

\title{
Trimorphism of N-methylurea: crystal structures, phase transitions and thermodynamic stabilities
}

\author{
G. Baaklini, G. Gbabode, S. Clevers, Philippe Négrier, Denise Mondieig, G. \\ Coquerel
}

\section{- To cite this version:}

G. Baaklini, G. Gbabode, S. Clevers, Philippe Négrier, Denise Mondieig, et al.. Trimorphism of Nmethylurea: crystal structures, phase transitions and thermodynamic stabilities. CrystEngComm, 2016, 18 (25), pp.4772-4778. 10.1039/c6ce00652c . hal-01344818

\author{
HAL Id: hal-01344818 \\ https://hal.science/hal-01344818
}

Submitted on 12 Jul 2016

HAL is a multi-disciplinary open access archive for the deposit and dissemination of scientific research documents, whether they are published or not. The documents may come from teaching and research institutions in France or abroad, or from public or private research centers.
L'archive ouverte pluridisciplinaire HAL, est destinée au dépôt et à la diffusion de documents scientifiques de niveau recherche, publiés ou non, émanant des établissements d'enseignement et de recherche français ou étrangers, des laboratoires publics ou privés.

\section{다(1)(2)}

Distributed under a Creative Commons Attribution - ShareAlikel 4.0 International 


\title{
Trimorphism of $\mathbf{N}$-methylurea: crystal structures, phase transitions and thermodynamic stabilities $\uparrow$
}

\author{
G. Baaklini, ${ }^{a}$ G. Gbabode, ${ }^{a}$ S. Clevers, ${ }^{a b}$ P. Négrier, ${ }^{c}$ D. Mondieig ${ }^{\mathrm{c}}$ and G. Coquerel ${ }^{\star a}$
}

\begin{abstract}
Melt crystallization of $\mathrm{N}$-methylurea (NMU) was investigated by X-ray and differential scanning calorimetry (DSC) techniques. In addition to the known orthorhombic stable Form I, two new polymorphic forms (II and III) crystallizing in the centrosymmetric space group $P 2_{1} / C$ were obtained at different quenching tem-peratures. The crystal structures of Forms II and III were determined from X-ray powder diffraction data. The crystallographic results for the monoclinic forms are presented in this study, as well as a detailed com-parison of crystal structures of the three polymorphs. The nature of hydrogen bonds in Form II and Form III were found to be similar; hence, a first order mechanism governed by means of shear movements is suggested where a transition via nucleation and growth could occur at low temperatures. The relative thermodynamic stabilities of the three forms of NMU were investigated by DSC analyses. Form II and Form III exhibited a reversible solid solid phase transition at circa $-118^{\circ} \mathrm{C}$. Both forms were found to be mono-tropically related to the stable Form I.
\end{abstract}

\section{Introduction}

$N$-Methylurea (NMU), molecular structure shown in Fig. 1, is a hygroscopic non-linear optical material. ${ }^{1}$ Many co-crystals and salts of NMU are reported in the literature. ${ }^{2-5}$ Up to this study, the only known crystal structure of NMU is a stable form that was first proposed in $1933,{ }^{6}$ the structure was solved in 1976 by Huiszoon and Tiemessen ${ }^{7}$ and lastly refined at $8 \mathrm{~K}$ by Chęcińska et al. ${ }^{8} \mathrm{NMU}$ crystallizes in the orthorhombic system with the chiral (therefore non-centrosymmetric) space group $P 2_{1} 2_{1} 2_{1}$. Several studies investigated the enthalpies and entropies of fusion and solid-solid transition of urea, and its derivatives, including NMU where only the enthalpy of fusion of NMU has been reported..$^{9-11}$ Hence, one can notice that the thermal programs applied in these studies consisted in first cooling down the NMU sample then heating up to melting.

In the present work, our experiments provide evidence of two metastable polymorphic forms of NMU obtained by meltcrystallization at different quenching temperatures. Thereafter, we report the crystal structures and stability relationships

\footnotetext{
${ }^{a}$ Normandie Univ, Laboratoire SMS EA3233, Univ Rouen, Mont Saint Aignan, France. E mail: gerard.coquerel@univ rouen.fr

${ }^{b}$ Laboratoire de Chimie des Polymères, Faculté des Sciences, Université Libre de Bruxelles (ULB), CP 206/1, Boulevard du Triomphe, 1050 Bruxelles, Belgium ${ }^{c}$ LOMA, UMR 5798, Université Bordeaux, 351 Cours de la Libération, F 33400 Talence, France

$\dagger$ Electronic supplementary information (ESI) available: Supplementary informa tion include crystal structure determination and molecular chains of Form III. CCDC 1464782 and 1464783. For ESI and crystallographic data in CIF or other electronic format see DOI: 10.1039/c6ce00652c
}

between the three polymorphs of NMU by X-ray diffraction and DSC analyses.

\section{Materials and methods}

\subsection{Materials}

NMU was acquired from Sigma Aldrich and used without further purification.

\subsection{Methods}

2.2.1 X-Ray powder diffraction (XRPD). Melt crystallization experiments were conducted in capillaries. Commercial NMU was introduced in $0.5 \mathrm{~mm}$ diameter Lindemann glass capillaries and heated up to fusion, then directly quenched at a predetermined temperature using a cryostat fed with liquid nitrogen (Oxford Cryosystems). The capillaries were mounted on an Inel CPS 120 diffractometer that works in a typical Debye-Scherrer transmission geometry $\left(\mathrm{CuK} \alpha_{1}\right.$ radiation $-\lambda=$ $0.15406 \mathrm{~nm}$ - as incident beam) where diffracted rays are simultaneously collected on a $120^{\circ}$ position sensitive curved counter by gas ionization (argon $+\mathrm{C}_{2} \mathrm{H}_{6}$ ). The glass capillaries are rotated around their axis all along the experiment in order to minimize preferential orientation of crystallites. External calibration to convert the measured 4096 channels to $2 \theta$

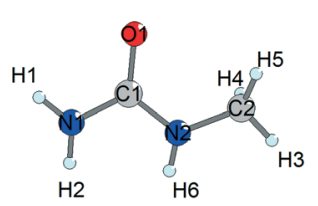

Fig. 1 Molecular structure of $N$ methylurea. 
degrees was applied using cubic $\mathrm{Na}_{2} \mathrm{Ca}_{2} \mathrm{Al}_{2} \mathrm{~F}_{4}$ (high angle calibration) $^{12}$ mixed with silver behenate (low angle calibration). ${ }^{13}$ Measurements were performed on the quenched samples at different temperatures during the whole day or overnight in order to obtain reflections with exploitable intensities.

2.2.2 DSC analyses. Two types of DSC were used:

A heat flux DSC that served to determine the melting points and the enthalpy of fusion of Form I and Form II. The thermal analyses were performed using a DSC 214 Polyma (Netzsch). Samples were weighed in $25 \mu \mathrm{L}$ aluminum pans and a heating rate of $5 \mathrm{~K} \mathrm{~min}{ }^{1}$ was applied, under nitrogen atmosphere. Data treatment was performed using Netzsch Proteus ${ }^{\circledR}$ software v6.1.

A power-compensated DSC was also used in order to reach low temperatures down to $150{ }^{\circ} \mathrm{C}$.

The thermal analyses were conducted in a powercompensated Perkin Elmer Pyris Diamond DSC equipped with a liquid nitrogen cooling system. Solid samples (mass $\sim 5$ $\mathrm{mg}$ ) were placed in a $30 \mu \mathrm{L}$ pierced aluminum crucible. The atmosphere of the analyses was regulated by nitrogen flux (20 $\mathrm{mL} \min { }^{1}$ ), and heat runs were conducted at $5 \mathrm{~K} \mathrm{~min}{ }^{1}$. Data treatment was performed using Pyris-Thermal Analysis Software.

\section{Results}

\subsection{X-Ray analyses of the melt-crystallized NMU}

The capillary containing the commercial NMU was heated up to the melting temperature and directly quenched at $173{ }^{\circ} \mathrm{C}$ and $50{ }^{\circ} \mathrm{C}$. X-ray analyses were performed at these temperatures. The comparison between the XRPD patterns of NMU obtained after melt quenching and the stable form reveals the crystallization of new forms at different quenching temperatures (Fig. 2). Indeed, the XRPD pattern recorded at 50 ${ }^{\circ} \mathrm{C}$ exhibits new characteristic peaks different from those observed for the stable form. Hence, this new phase will be assigned to as Form II (CCDC number: 1464782) whereas the stable form will be assigned to as Form I. The XRPD pattern recorded at $173^{\circ} \mathrm{C}$ also reveals new characteristic peaks dif-

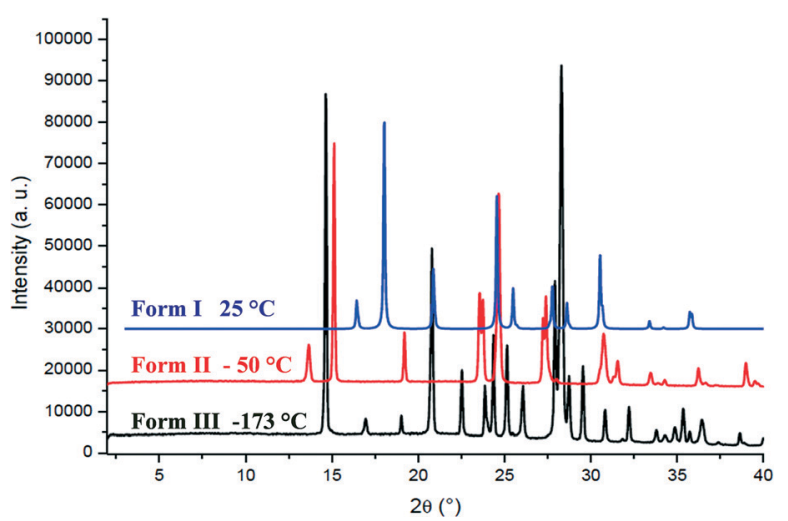

Fig. 2 XRPD patterns of the NMU stable form at $25^{\circ} \mathrm{C}$ (blue) and after melt quenching at $-50^{\circ} \mathrm{C}$ (red) and $-173{ }^{\circ} \mathrm{C}$ (black). ferent from Form II and Form I. Hence, this new phase will be assigned to as Form III (CCDC number: 1464783). The $2 \theta$ positions of characteristic reflections of Forms I, II and III are summarized in Table 1.

Temperature-resolved (TR)-X-ray analyses on NMU forms. TR-X-ray analyses were performed between $163{ }^{\circ} \mathrm{C}$ and 113 ${ }^{\circ} \mathrm{C}$ with a heating rate of $1{ }^{\circ} \mathrm{C} \mathrm{min}{ }^{1}$ (Fig. 3) between two subsequent measurements (a time lag of 4 minutes at the desired temperature was kept before each measurement). Each analysis lasted for 30 minutes at the defined temperature.

Upon heating from $163{ }^{\circ} \mathrm{C}$, characteristic peaks of Form III start decreasing in intensity between $143^{\circ} \mathrm{C}$ and $138^{\circ} \mathrm{C}$. These peaks completely disappear at $123{ }^{\circ} \mathrm{C}$ where the transition seems to be completed. On the other hand, characteristic peaks of Form II appear in the same range of temperature and are the only ones observed at $123{ }^{\circ} \mathrm{C}$.

The transition between Form II and Form III was found to be reversible upon heating and cooling (data not shown).

\subsection{Crystal structures of Form I, II and III}

Fig. 4 and 5 display the comparison between the X-ray diffraction patterns calculated from the crystal structure solved from X-ray powder data and the measured ones for Form II and III, respectively. The agreement is very good for Form II $(\mathrm{Rwp}=7.3 \%)$ as shown by the almost flat difference curve in Fig. 4 and a little less for Form III $($ Rwp $=10.6 \%)$ as shown in Fig. 5. The differences might be due to preferential orientation effects, which might be more severe at very low temperatures. Crystallographic data determined for Forms II and III

Table 1 Characteristic peaks of Form I, II and III

\begin{tabular}{lll}
\hline Form I $\left(25^{\circ} \mathrm{C}\right)$ & Form II $\left(-50^{\circ} \mathrm{C}\right)$ & $\frac{\text { Form III }\left(-173^{\circ} \mathrm{C}\right)}{2 \theta}$ \\
\cline { 2 - 3 } $2 \theta\left(^{\circ}\right)$ & $2 \theta\left(^{\circ}\right)$ & 14.6 \\
\hline 16.6 & 13.7 & 16.9 \\
18.1 & 15.1 & 20.8 \\
20.9 & 19.2 & 22.5 \\
24.5 & 23.6 & 25.1 \\
25.5 & 24.7 & 28.3 \\
27.8 & 27.4 &
\end{tabular}

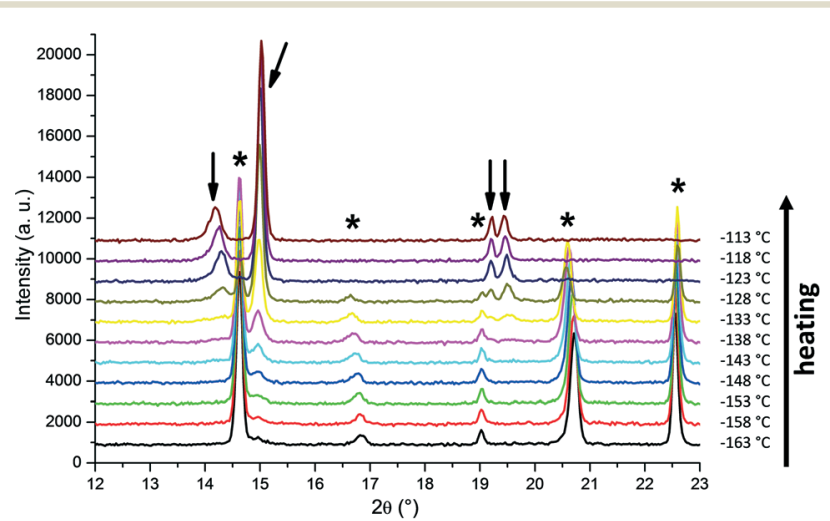

Fig. 3 TR $X$ ray diffraction patterns obtained upon heating Form III, represented in the [12 23] $2 \theta$ range. Characteristic peaks of Form II are marked with arrows while those of Form III are marked with an "*". 


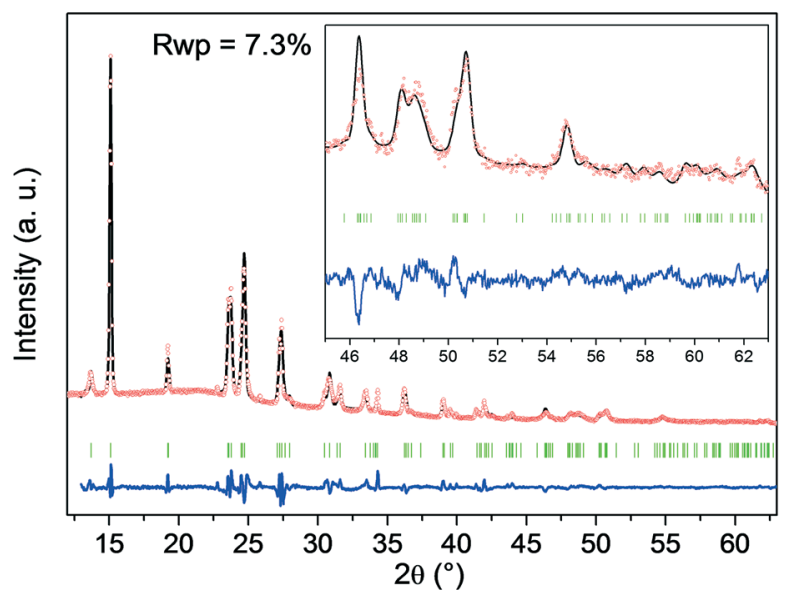

Fig. 4 Experimental (red) and calculated (black) XRPD patterns for the crystal structure of Form II at $-50{ }^{\circ} \mathrm{C}$. Systematic existences calculated from the monoclinic unit cell (green ticks) and difference between calculated and experimental XRPD patterns (blue). The inset represents a zoom on the higher angle $2 \theta$ domain [45 63].

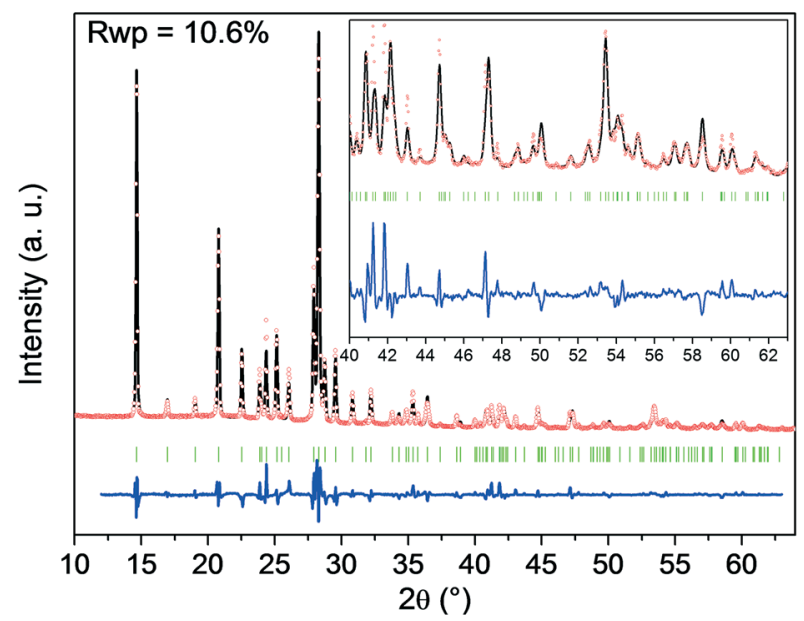

Fig. 5 Experimental (red) and calculated (black) XRPD patterns for the crystal structure of Form III at $-173{ }^{\circ} \mathrm{C}$. Systematic existences calculated from the monoclinic unit cell (green ticks) and difference between calculated and experimental XRPD patterns (blue). The inset represents a zoom on the higher angle $2 \theta$ domain [40 $63^{\circ}$ ].

are given in Table 2 together with those for Form I for the sake of comparison. Forms II and III both crystallize in a $P 2_{1} / c$

Table 2 Crystal data for Forms I, II and III

\begin{tabular}{|c|c|c|c|}
\hline Form & (I) at $25^{\circ} \mathrm{C}$ & (II) at $-50^{\circ} \mathrm{C}$ & $\begin{array}{l}\text { (III) at } \\
-173{ }^{\circ} \mathrm{C}\end{array}$ \\
\hline $\begin{array}{l}\text { Crystal system, } \\
\text { space group }\end{array}$ & $\begin{array}{l}\text { Orthorhombic, } \\
P 2_{1} 2_{1} 2_{1}\end{array}$ & $\begin{array}{l}\text { Monoclinic, } \\
P 2_{1} / c\end{array}$ & $\begin{array}{l}\text { Monoclinic, } \\
P 2_{1} / c\end{array}$ \\
\hline$a(\AA)$ & $8.4767(6)$ & $4.6147(6)$ & $4.6604(3)$ \\
\hline$b(\AA)$ & $6.9809(5)$ & $6.5781(12)$ & $7.4079(7)$ \\
\hline$c(\AA)$ & $6.9227(6)$ & $12.9004(16)$ & $10.4566(6)$ \\
\hline$\beta\left(^{\circ}\right)$ & 90 & $90.418(5)$ & $92.007(4)$ \\
\hline$Z$ & 4 & 4 & 4 \\
\hline Density $\left(\mathrm{g} \mathrm{cm}^{3}\right)$ & $1.201(1)$ & $1.256(1)$ & $1.364(1)$ \\
\hline Volume $\left(\AA^{3}\right)$ & $410(1)$ & $392(1)$ & $361(1)$ \\
\hline
\end{tabular}

space group, thus suggesting a different packing of NMU molecules in those forms compared to Form I. The cell parameters of Form II are quite different from those of Form I, yet a similar unit cell volume is preserved. Indeed, the $a$ parameter of Form II is around half that of Form I while its $c$ parameter is almost twice that of Form I. The cell parameters of Form III are close to those of Form II but with a much lower value of $c$ (reduction from $12.9 \AA$ for Form II to $10.5 \AA$ for Form III). We will come back to this point later on in this manuscript.

Despite, the differences in unit cell dimensions and space groups between the two new polymorphs and Form I, the packing of the three forms appears to display a common feature based on the establishment of "V-shaped" (bifurcated) intermolecular hydrogen bonds (Table 3 ) that gives rise to molecular chains (Fig. 6) that spread along the $a$-axis for the three crystal structures. The hydrogen bond distances, as well as the angles, are relatively close in the three forms.

As shown in Fig. 6a, the molecules within the chains of Form I present different orientations, the methyl moieties are on both sides of the central axis of the molecular chain. Indeed, NMU molecules inside a chain are related by a $2_{1}$ screw axis parallel to the $a$-axis in Form I ( $P 2_{1} 2_{1} 2_{1}$ space group); while in the case of Forms II and III, they are related by a glide plane parallel to the $(a, c)$ plane $\left(P 2_{1} / c\right.$ space group). Furthermore, the chains have a zig-zag shape in Form I when viewed from the side (Fig. 6a, bottom) while they are fairly flat in Forms II and III (Fig. $6 \mathrm{~b}$ and c, bottom).

These chains are connected with each other through another type of hydrogen bond (Table 3) leading to the final arrangement in a three dimensional network for Form I (Fig. 7) and in layers for Forms II (Fig. 8) and III (Fig. 9).

In the case of Form II and Form III, the differences are quite small. They are due to a slight shift between the packing of the layers, while the differences between Form I and the other two forms are obvious: the different orientation of the methyl moieties along the molecular chains, and the three dimensional hydrogen bonding network that arises from this alternating orientation.

To emphasize the latter for Form I, the molecular chains are depicted in different colors in Fig. 7 (intra-chain = dashed pink line and inter-chain = dashed cyan line).

The availability of hydrogen bonds involved in the connection of the molecular chains in Form $\mathbf{I}$ is increased due to the different orientation of the methyl moiety and the "brickwall packing" of NMU between adjacent molecular chains.

Table 3 Hydrogen acceptor bond distances $(\mathrm{O} \cdots \mathrm{H})$ and angles of Forms I, II and III

\begin{tabular}{|c|c|c|c|c|c|}
\hline \multicolumn{2}{|l|}{ Form } & \multirow{2}{*}{$\frac{\text { I }}{2.08}$} & \multirow{2}{*}{$\frac{\text { II }}{2.08(1)}$} & \multicolumn{2}{|l|}{ III } \\
\hline $\mathrm{O}_{1} \cdots \mathrm{H}_{1} \quad \mathrm{~N}_{1}$ & Distance $(\AA)$ & & & $2.26(1)$ & Between molecula \\
\hline & Angle $\left({ }^{\circ}\right)$ & 167 & $168(1)$ & $162(1)$ & chains \\
\hline $\mathrm{O}_{1} \cdots \mathrm{H}_{2} \quad \mathrm{~N}_{1}$ & Distance $(\AA)$ & 2.22 & $2.17(1)$ & $2.17(1)$ & Establishment of \\
\hline & Angle (०) & 151 & $148(1)$ & $147(1)$ & 'V shaped' \\
\hline $\mathrm{O}_{1} \cdots \mathrm{H}_{6} \mathrm{~N}_{2}$ & Distance $(\AA)$ & 2.16 & $2.19(1)$ & $2.12(1)$ & intermolecular \\
\hline & Angle $\left({ }^{\circ}\right)$ & 159 & $152(1)$ & 155(1) & hydrogen bonds \\
\hline
\end{tabular}



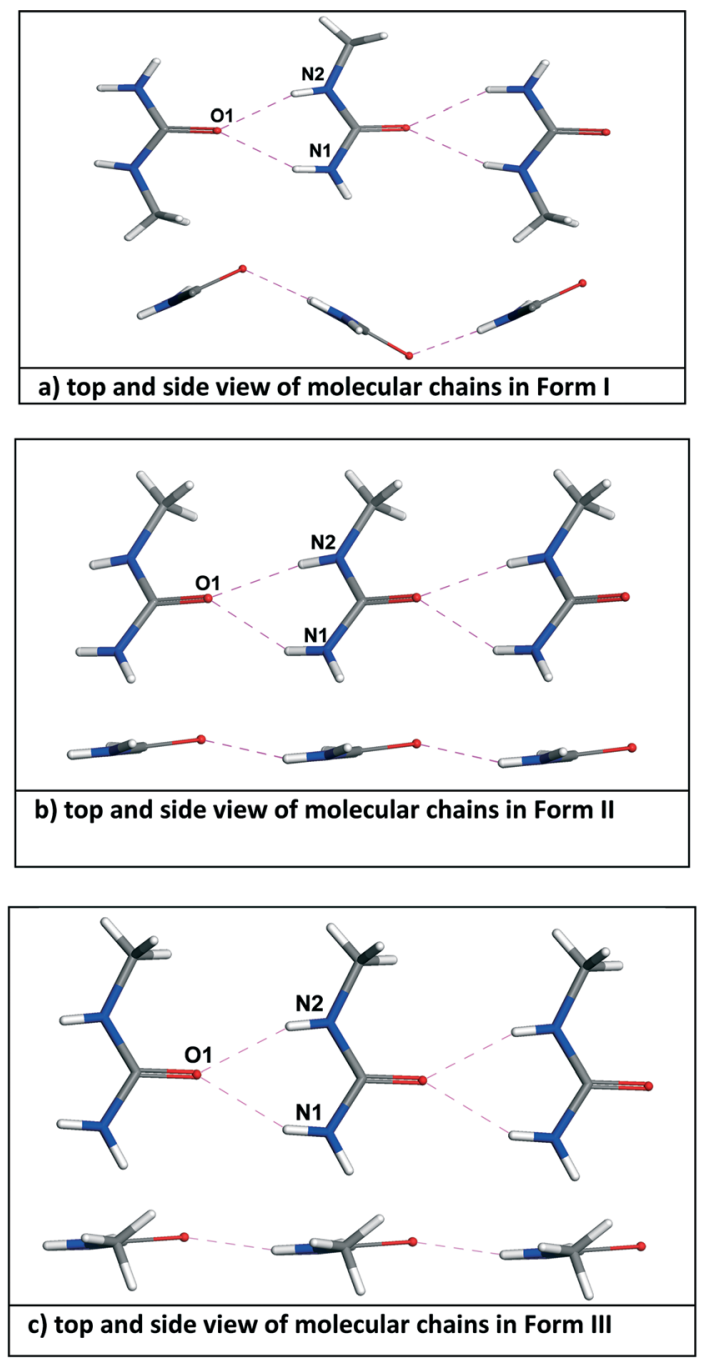

Fig. 6 Molecular chains built from hydrogen bonds (dashed pink lines) established between consecutive molecules along the $a$ axis in a) Form I, b) Form II, and c) Form III.

a)

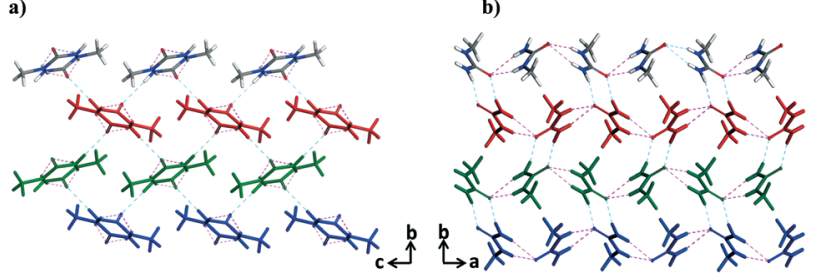

Fig. 7 Molecular chains of Form I along a) the $a$ axis and b) the $c$ axis.

Therefore, the density and the orientation of the hydrogen bonding network gives rise to an efficient three dimensional packing (Fig. 7).

Neighboring molecular chains in Forms II are also connected through a third type of hydrogen bond (the same color code as in Fig. 7 is kept for inter-chain (represented in dashed cyan lines) and intra-chain (represented in dashed pink lines)). The molecular chains in Form II are oriented in an anti-parallel way and generate layers in the $(a, b)$ plane
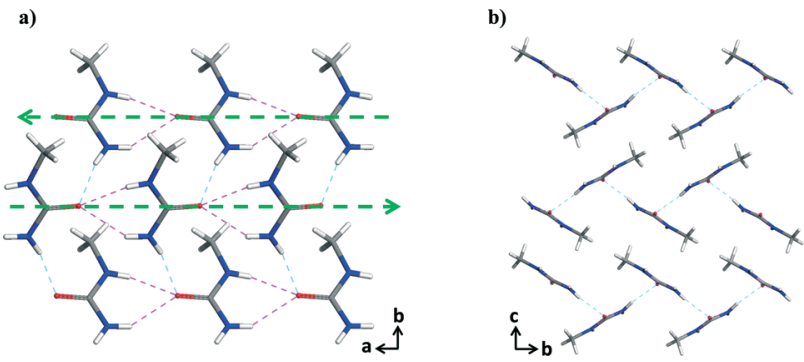

Fig. 8 Molecular chains of Form II along a) the $c$ axis and b) the $a$ axis showing methyl moieties face to face from adjacent layers.
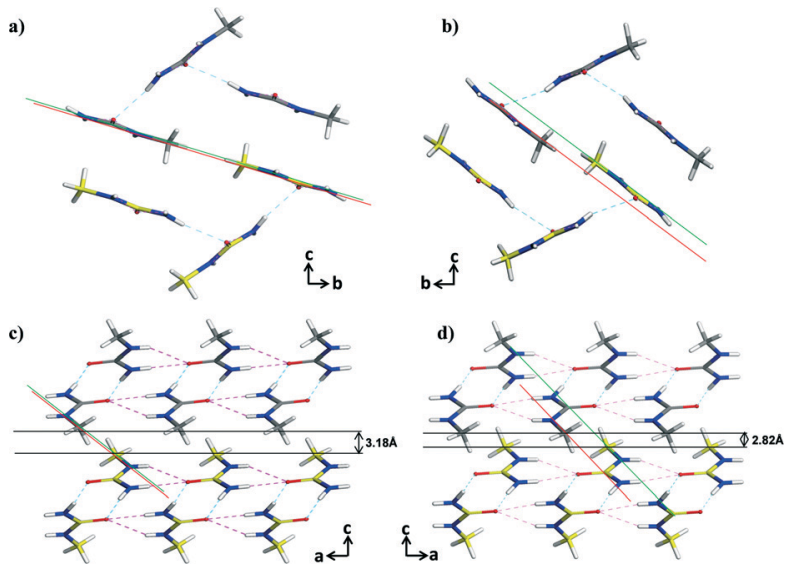

Fig. 9 Comparison between the crystal structures of Form II represented along a) the $a$ axis and $c$ ) the $b$ axis and Form III repre sented along b) the $a$ axis and d) the $b$ axis illustrating a shift of methyl moieties in Form III. Carbon atoms colored in yellow correspond to the lower layer. The red and green segments show the alignment of methyl groups.

that pack along the $c$-axis through inter-chain hydrogen bonds on one side and methyl-methyl contacts on the other (Fig. 8).

A similar packing is observed for Form III (see Fig. S1 in ESI $\dagger$ ). The major difference between Forms II and III lies in the packing arrangement of the layers along the $c$-axis. Hence, it can be noticed that the consecutive layers in Form III are shifted so that the steric hindrance generated by the methyl moieties is limited (Fig. 9b-d) while in Form II, the methyl groups are almost oriented face to face (Fig. 9a-c).

\subsection{Stability relationship between the three forms of NMU}

$\mathrm{X}$-Ray results were completed by thermal analysis measurements. Thus, the stability behavior and the thermodynamic relationships between Forms I, II and III were investigated.

The melt quenching process was reproduced inside the crucible as follows: starting from the commercial batch of Form I, the sample was heated until melting at $5 \mathrm{~K}$ min ${ }^{1}$. The liquid melt was then rapidly cooled down to $50^{\circ} \mathrm{C}$ or to $150{ }^{\circ} \mathrm{C}$ with a cooling rate of $20 \mathrm{~K} \mathrm{~min}{ }^{1}$ (fastest cooling rate accessible by the DSC apparatus). The sample was heated again at $5 \mathrm{~K}$ min ${ }^{1}$ up to $130{ }^{\circ} \mathrm{C}$.

Data obtained from the quenching experiment at $50{ }^{\circ} \mathrm{C}$. During the first heating of the commercial batch, the DSC 
thermogram shows an endothermic peak at $98{ }^{\circ} \mathrm{C}\left(\Delta H_{\mathrm{F}}^{\mathrm{I}}=\right.$ 188.5 $\mathrm{J} \mathrm{g}^{1}$ ) that was assigned to the fusion of Form I. During the second heating, the DSC thermogram shows an endothermic peak at $95.2{ }^{\circ} \mathrm{C}\left(\Delta H_{\mathrm{F}}^{\mathrm{II}}=166.6 \mathrm{~J} \mathrm{~g}{ }^{1}\right)$ that was assigned to the fusion of Form II (Fig. 10). This strongly indicates that Forms I and II have a monotropic relationship (Form I being the most stable form) because Form I has an enthalpy of fusion and temperature of fusion higher than that of Form II (this is in agreement with the Burger and Ramberger rules ${ }^{14}$ ). Besides this, an X-ray diffraction follow-up of Form II revealed a spontaneous conversion of Form II to Form I within a few days of storage at room temperature. The kinetics of this return to thermodynamic equilibrium is greatly influenced by moisture adsorbed by the compound.

Data obtained from the quenching experiment at $150{ }^{\circ} \mathrm{C}$. The same thermal program was applied for these quenching experiments at $150{ }^{\circ} \mathrm{C}$ (Fig. 11).

Different thermal events are detected by DSC analysis upon cooling from the melt and the second heating that starts at $150{ }^{\circ} \mathrm{C}$.

The following observations can be noted:

Upon cooling from the melt, Form II is crystallized upon solidification of the melt. This crystallization is illustrated by a sharp exothermic peak with an onset at $\sim 51^{\circ} \mathrm{C}$. Three additional exothermic peaks are observed just after this recrystallization. These events are likely to be the successive solidifi-

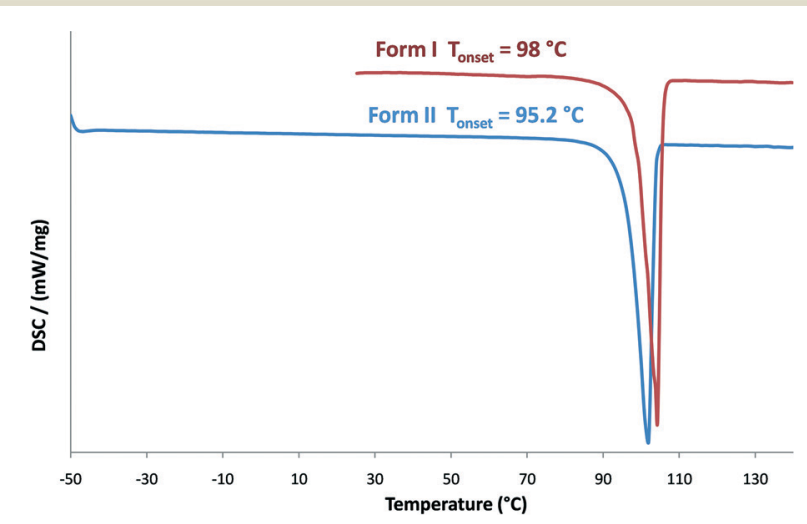

Fig. 10 DSC curves of the commercial NMU upon first (upper curve) and second (lower curve) heating.

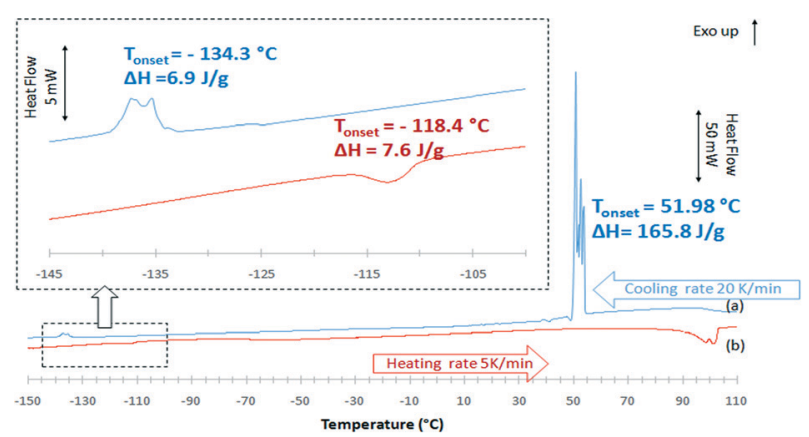

Fig. 11 DSC curves of NMU upon a) cooling from the melt (cooling rate: $20 \mathrm{~K} \mathrm{~min}^{-1}$ ) followed by b) heating up to the melt (heating rate: $5 \mathrm{~K} \mathrm{~min}^{-1}$ ). cations of scattered drops of the melt inside the crucible. Upon further cooling, another exothermic peak with an onset at circa $134{ }^{\circ} \mathrm{C}$ is detected. This peak would correspond to the reversible solid-solid transition Form II $\rightarrow$ Form III with hysteresis (Fig. 11a).

Upon heating, an endothermic peak with an onset at 118 ${ }^{\circ} \mathrm{C}$, corresponding to solid-solid transition Form III $\rightarrow$ Form II, is detected (Fig. 11b). It can be inferred from the hysteresis phenomenon and the detection of a (weak) enthalpy that this transition is of a first order. The mechanism of phase transition between Form II and Form III should then proceed through nucleation and growth.

Upon further heating, two endothermic peaks close to each other are observed: the first one corresponding to the fusion of Form II and the second one corresponding to the fusion of Form I (Fig. 11b).

A rough approximation of the enthalpy of fusion of Form III can be calculated as follows:

$$
\begin{aligned}
\Delta H_{\mathrm{F}}^{\mathrm{III}} & =\Delta H_{\mathrm{F}}^{\mathrm{II}}+\Delta H_{\mathrm{t}}^{\mathrm{III} \rightarrow \mathrm{II}} \\
& =166.6+7.6 \\
& =174.2 \mathrm{~J} \mathrm{~g}^{-1}
\end{aligned}
$$

The comparison between the enthalpies of fusion of the three forms shows that:

$$
\Delta H_{\mathrm{F}}^{\mathrm{I}}>\Delta \mathrm{H}_{\mathrm{F}}^{\mathrm{III}}>\Delta H_{\mathrm{F}}^{\mathrm{II}}
$$

In order to verify that Form I was not formed during the quenching procedure, the same protocol of quenching of DSC at $50{ }^{\circ} \mathrm{C}$ and $150{ }^{\circ} \mathrm{C}$ was reproduced in second harmonic generation (SHG). No SHG signal was detected at these temperatures. This indicated that Form I is not present at these temperatures since this optical non-linear sensitive (ppm levels) technique gives rise to a signal only if the compound crystallizes in a non-centrosymmetric space group ${ }^{15}$ (which is the case of Form $I$ crystallizing in $P 2_{1} 2_{1} 2_{1}$ and not the case for Form II and III that crystallize in $P 2_{1} / c$ ).

All investigations presented above prove that Form $\mathbf{I}$ is the thermodynamically stable form whatever the temperature. Form II and III are monotropically related to Form I. A reversible solid-solid transition between Form II and III was found at $118{ }^{\circ} \mathrm{C}$ using DSC. The discrepancy between the solidsolid transition temperatures observed by DSC and X-ray diffraction is most likely due to kinetics. Indeed, it is observed by X-ray diffraction that the complete transition of Form II $\rightarrow$ Form III occurs in a range of more than $15^{\circ} \mathrm{C}$ (between 143 ${ }^{\circ} \mathrm{C}$ and $128^{\circ} \mathrm{C}$, see Fig. 3), thus indicating the slow kinetics of the solid-solid transition. Moreover, the X-ray diffraction analyses are considered as static measurements (each X-ray analysis lasted 30 minutes at a given temperature with a lag time of 4 minutes and a heating rate of $1^{\circ} \mathrm{C}$ per minute between two temperatures), while the DSC analyses are considered as dynamic measurements. Given the slow kinetics of the solid-solid transition, it is difficult to compare the temperatures obtained by both techniques. Anyway, we chose to 
consider the temperature obtained by DSC as the most accurate evaluation of the actual transition temperature since the precise regulation of temperature of a capillary is more difficult than that of a DSC crucible (see Fig. 11).

\subsection{Mechanism of transition from Form II to Form III}

It was interesting to suggest a mechanism of transition between Form II and Form III, especially since this transition occurs at low temperatures.

As shown previously, Form II and Form III present common features: they crystallize in the same space group $\left(P 2_{1} / c\right)$, they have the same asymmetric unit $\left(Z^{\prime}=1\right)$ and they present the same packing of NMU molecules characterized by molecular chains arranged in layers through hydrogen bonds and methyl-methyl contacts.

However, some differences still exist between the two structures, particularly at the methyl-methyl interface. Indeed, the distance between adjacent layers connected through methyl-methyl contacts was found to be $3.18 \AA$ for Form II (at $50^{\circ} \mathrm{C}$ ) and $2.82 \AA$ for Form III (at $173{ }^{\circ} \mathrm{C}$ ), see Fig. $9 \mathrm{c}$ and $\mathrm{d}$. This shortening is consistent with the reduction of the $c$ parameter from Form II to Form III, shown in section 3.2, and whose evolution as a function of temperature is displayed in Fig. 12 together with that of the unit cell volume. It appears that, upon cooling Form II, the crystal lattice is monotonically compressed until a certain point (the II $\rightarrow$ III transition temperature) at which a discontinuous decrease of the unit cell volume occurs, indicating a transformation into Form III.

Interestingly, the II $\rightarrow$ III transition (or vice versa) is found to be fully reversible at moderate to high heating/cooling rates despite the poor diffusion at low temperature.

We hypothesize that, upon cooling Form II, the contraction of the lattice could generate steric hindrance on the methyl moieties. This issue is overcome by a cooperative slide of the layers along the $(b, c)$ plane, as shown in Fig. 8 and 9, giving rise to the stabilization of Form III. Hence, the methyl moieties are shifted in Form III, contrary to Form II, where methyl moieties are aligned (Fig. 9). Our hypothesis is also valid the other way around, that is, upon heating Form III.

In the light of all these results, we can suggest that the transition between Form II and Form III is of first order as a)

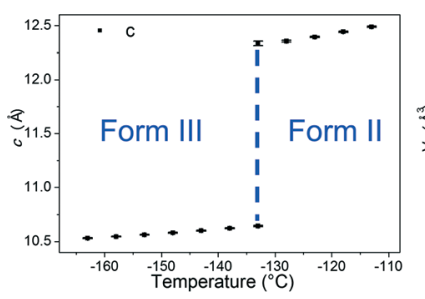

b)

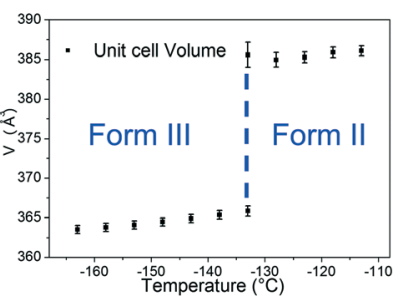

Fig. 12 Evolution of the a) $c$ parameter b) unit cell volume of NMU as a function of temperature (from -163 to $-113^{\circ} \mathrm{C}$ ). The different values have been determined from the $X$ ray diffraction patterns shown in Fig. 3. The dashed blue vertical line delimits the respective stability do mains of Forms II and III established from this data. shown by the discontinuous changes in enthalpy (Fig. 11) and unit cell volume (Fig. 12) observed at the phase transition temperature. It should then proceed through nucleation and growth of crystals of Form II (resp. Form III) at the expense of crystals of Form III (resp. Form II) upon cooling (resp. heating). The significant temperature hysteresis observed between II $\rightarrow$ III and III $\rightarrow$ II transitions (Fig. 11), suggesting an activated process, is consistent with this postulate. The full reversibility experimentally observed might be related to the small amplitude of the movements necessary to switch from one form to another, which might be achievable even at low values of thermal motion.

\section{Conclusion}

Quenching experiments on NMU at two different temperatures allowed us to discover two polymorphs of NMU (designated as Form II and Form III). As far as we know, these have not been reported before. The crystal structure of the two forms were solved from X-ray diffraction powder data and it appears that both forms crystallize in the centrosymmetric space group $P 2_{1} / c$, contrary to the known commercially available NMU (Form I) crystallizing in the non-centrosymmetric space group $P 2_{1} 2_{1} 2_{1}$.

Comparisons between the crystal structures of Forms II and III reveal extensive similarities between them, including the hydrogen bonding network. Besides this, the "V-shaped" hydrogen bonds between NMU molecules observed in Form I also constitute the main building units at the origin of the packing arrangement of Forms II and III.

A mechanism is suggested to explain the reversible conversion at $118{ }^{\circ} \mathrm{C}$ and the transition is first order. Indeed, there is a discontinuity change in entropy and enthalpy with a small, but significant, hysteresis effect. The transformation could take place by nucleation and growth featuring limited shear movements and a self-templating effect. Form I is found to be the most stable phase (Forms II and III are monotropically related to Form I) as shown by DSC and X-ray diffraction measurements. This result is clearly consistent with the crystal structure of Form I that provides the most efficient packing arrangement of NMU molecules through a complete three dimensional hydrogen bonding network. However, upon fast crystallization (such as melt-quenching), this complex arrangement might not have time to settle and alternative structures with less efficient packing, such as Forms II and III, are kinetically favored.

The present article is another evidence that even for a small rigid molecule such as NMU with highly directional interactions, a rich polymorphic behavior can be revealed by suitably modifying the conditions of crystallization of this compound. Indeed, the three reported crystal structures of NMU can be viewed as the results of alternative crystal packing arrangements of the same building units (NMU molecules connected through V-shaped hydrogen bonds) or "supramolecular synthons" in the concept of crystal engineering. ${ }^{16}$ 


\section{Acknowledgements}

This research was supported by the grant of Région HauteNormandie. We would like to thank Prof. Yves Geerts for hosting S. C and for giving access to the power-compensated DSC. We also thank Dr. Valérie Dupray, Dr. Morgane Sanselme and Lina Yuan for their contribution.

\section{References}

1 E. E. A. Shepherd, J. N. Sherwood and G. S. Simpson, J. Cryst. Growth, 1996, 167(3), 709-715.

2 A. O. Jones, C. K. Leech, G. J. McIntyre, C. C. Wilson and L. H. Thomas, CrystEngComm, 2014, 16(35), 8177-8184.

3 J. H. Bryden, Acta Crystallogr., 1957, 10(11), 714-714.

4 A. J. Rybarczyk-Pirek, Struct. Chem., 2012, 23(6), 1739-1749.

5 S. Harkema, J. H. M. Ter Brake and H. J. G. Meutstege, Acta Crystallogr., Sect. B: Struct. Crystallogr. Cryst. Chem., 1979, 35(9), 2087-2093.

6 R. B. Corey and R. W. Wyckoff, Z. Kristallogr., 1933, 85(1), 132-142.
7 C. Huiszoon and G. W. M. Tiemessen, Acta Crystallogr., Sect. B: Struct. Crystallogr. Cryst. Chem., 1976, 32(5), 1604-1606.

8 L. Chęcińska, W. Morgenroth, C. Paulmann, D. Jayatilaka and B. Dittrich, CrystEngComm, 2013, 15(11), 2084-2090.

9 G. Della Gatta and D. Ferro, Thermochim. Acta, 1987, 122(1), 143-152.

10 P. Ferloni and G. Della Gatta, Thermochim. Acta, 1995, 266, 203-212.

11 G. Y. Kabo, E. A. Miroshnichenko, M. L. Frenkel, A. A. Kozyro, V. V. Simirskii, A. P. Krasulin, V. P. Vorob'eva and Y. A. Lebedev, Russ. Chem. Bull., 1990, 39(4), 662-667.

12 M. Evain, P. Deniard, A. Jouanneaux and R. Brec, J. Appl. Crystallogr., 1993, 26, 563-569.

13 T. C. Huang, H. Toraya, T. N. Blanton and Y. Wu, J. Appl. Crystallogr., 1993, 26, 180-184.

14 A. Burger and R. Ramberger, Microchim. Acta, 1979, 72(3-4), 259-271.

15 S. Clevers, F. Simon, V. Dupray and G. Coquerel, J. Therm. Anal. Calorim., 2013, 112(1), 271-277.

16 G. R. Desiraju, Angew. Chem., Int. Ed. Engl., 1995, 34(21), 2311-2327. 